\title{
Estereótipos de pessoas com deficiência: competência versus cordialidade na questão das cotas
}

\author{
Maristela Ferro Nepomuceno \\ Maria Nivalda de Carvalho-Freitas
}

\section{RESUMO}

A Lei de Cotas em concurso público promove a inserção das pessoas com deficiência no mercado de trabalho, buscando minimizar desigualdades historicamente construídas. Para a compreensão desse fenômeno, esse estudo buscou compreender a percepção de servidores públicos a respeito da Lei de Cotas para as pessoas com deficiência e os estereótipos atribuídos a elas. Foram analisadas 44 entrevistas com funcionários de uma organização pública através da análise de conteúdo e da teoria do Modelo de Conteúdo de Estereótipo (MCE). Os resultados mostraram que, apesar da predominância de concordância com a Lei de Cotas, ainda podem ser identificadas críticas à reserva de vagas, atribuindo a essa ação a pena de violação do princípio da isonomia e de privilégio. As pessoas com deficiência passam a ser vistas como ameaças para algumas pessoas, o que pode ser interpretado como uma alteração das dimensões sociais do MCE mudando de alta cordialidade e baixa competência para baixa cordialidade e baixa competência. Esses resultados indicam a importância de ampliar ações organizacionais, adicionais ao cumprimento da Lei, com vistas a minimizar as exclusões sociais. Limites da pesquisa e possibilidades de contribuição para a ampliação do conhecimento e para a prática também são discutidos.

Palavras-chave: estereótipos; pessoa com deficiência; lei de cotas; cordialidade; competência.

\section{ABSTRACT}

\section{Disabled people stereotypes: competence versus cordiality in quota issues}

The Quota Law in public tenders promotes the insertion of disabled people in the labour market, seeking to minimize inequalities historically constructed. To understand this phenomenon, this study sought to understand the perception of public servants regarding the Quota Law for disabled people and the stereotypes attributed to them. 44 interviews with employees of a public organization were analyzed through content analysis and the theory of the Stereotype Content Model (MCE). The results showed that, in spite of the predominance of agreement with the Quota Law, criticisms of the reservation of vacancies can still be identified, attributing to this action the penalty of violation of the principle of isonomy and privilege. Disabled people are seen as threats to some people, which can be interpreted as a change in the social dimensions of $\mathrm{MCE}$, changing from high cordiality and low competence to low cordiality and low competence. These results indicate the importance of expanding organizational actions, in addition to complying with the Law, in order to minimize social exclusions. Limits of research and possibilities of contribution to the expansion of knowledge and practice are also discussed.

Keywords: stereotypes; disabled people; quota law; cordiality; competence.

As organizações públicas e privadas têm enfrentado alguns desafios no momento da contratação de pessoas com deficiência devido tanto ao desconhecimento da deficiência em si (Suzano et al., 2008), quanto às atitudes e preconceitos relacionados a elas (Antonak \& Livneh, 2000; Carvalho-Freitas \& Stathi, 2017; Ren, Paetzold, \& Colella, 2008; Ribeiro \& Carneiro, 2009; Stone \& Colella, 1996). Os estereótipos negativos em torno desse grupo minoritário persistem

\section{Sobre os autores}

M. F. N.

http://orcid.org/0000-00015817-022X

Universidade Federal de São João del-Rei - São João del-Rei, MG

maristelafnep@gmail.com

M. N. C. F.

http://orcid.org/0000-00017071-7179

Universidade Federal de São João del-Rei - São João del-Rei, MG

nivalda@ufsj.edu.br

\section{Direitos Autorais}

Este é um artigo de acesso aberto e pode ser reproduzido livremente, distribuído, transmitido ou modificado, por qualquer pessoa desde que usado sem fins comerciais. 0 trabalho é disponibilizado sob a licença Creative Commons CC-BY-NC.

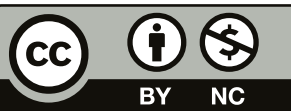




\section{H. INTERACÃOEM PSICOLOGIA}

em todo o mundo (Carvalho-Freitas \& Stathi, 2017; Louvet, 2007; Louvet et al., 2009; Rohmer \& Louvet, 2012; Stone \& Colella, 1996). No Brasil, a inclusão das pessoas com deficiência no trabalho é assegurada pelo implemento da legislação antidiscriminação, denominada Lei de Cotas, designada para reduzir as disparidades sociais, dentre elas, as barreiras sociais, como o estereótipo e o preconceito junto a essas pessoas (Brasil, 1991). Os estereótipos negativos em torno desse grupo minoritário persistem em todo o mundo (Carvalho-Freitas \& Stathi, 2017; Louvet, 2007; Louvet et al., 2009; Rohmer \& Louvet, 2012; Stone \& Colella, 1996). No Brasil, a inclusão das pessoas com deficiência no trabalho é assegurada pelo implemento da legislação antidiscriminação, denominada Lei de Cotas, designada para reduzir as disparidades sociais, dentre elas, as barreiras sociais, como o estereótipo e o preconceito junto a essas pessoas (Brasil, 1991).

Essa política afırmativa é coerente com uma das principais teorias que visa compreender a redução do preconceito e promover atitudes positivas no grupo de trabalho, por meio da teoria do contato intergrupal de Gordon Allport (1954), em seu livro clássico The Nature of Prejudice. 0 autor afirma que o contato positivo e frequente entre pessoas de diferentes grupos contribui para melhorar a percepção ou julgamento de todo o grupo. Para que o contato seja efetivo na redução do preconceito, ele precisa ocorrer em condições apropriadas: cooperação, status igual, objetivos comuns e apoio de instituições e autoridades. Essa teoria foi corroborada por outras investigações (Carvalho-Freitas \& Stathi, 2017; Pettigrew \& Tropp, 2006; Vezzali \& Giovannini, 2011). No entanto, de acordo com Ribeiro e Carneiro (2009) há uma baixa receptividade da Lei de Cotas dentro das organizações. Em pesquisa mais antiga realizada por Lewis e Allee (1992) os autores afirmaram que as pessoas com deficiência enfrentam dificuldades tanto quando entram em uma organização, quanto na questão de progressão de carreira.

Esta realidade, apresentada pelos autores, não difere da situação atual na qual pesquisas mostram que mesmo com a imposição de leis que garantam o acesso desse grupo de pessoas no mercado de trabalho, há diversos fatores que dificultam a inserção de modo adequado, dentre esses, estão algumas barreiras tais como o despreparo das chefias e das organizações, a desconsideração das possibilidades de trabalho das pessoas com deficiência, a escassez de pessoas qualificadas para o trabalho, e dificuldades relacionadas à carreira (Assunção, Carvalho-Freitas, \& Oliveira, 2015; CarvaIho-Freitas, Tette, Souza, Bentivi, \& Oliveira, 2019; Costa, Carvalho-Freitas, \& Freitas, 2019; Carmo, Gilla \& Quitério, 2020; Neves-Silva, Prais, \& Silveira, 2015; Pereira, Bizelli, \& Leite, 2017; Rezende, Carvalho-Freitas, \& Vieira-Silva, 2016).

As barreiras sociais, como atitudes e crenças negativas, são o maior obstáculo à igualdade de oportunidades entre
Maristela Ferro Nepomuceno e Maria Nivalda de Carvalho-Freitas

funcionários com deficiência (Stone \& Colella, 1996). Estudos mostram que esse grupo enfrenta forte discriminação no mercado de trabalho, tal como as percepções negativas sobre as suas habilidades e competências relacionadas ao trabalho e a ocupação, embora possuam crenças positivas sobre as qualidades pessoais (Cohen et al., 2019). Essa ambiguidade de percepções relacionadas a esse grupo minoritário encontra amparo no trabalho de Fiske, Cuddy e Glick (2007). Todos esses fatores que dificultam a inclusão adequada, podem ser vistos como barreiras que podem reforçar ou aumentar as crenças e estereótipos em relação às pessoas com deficiência como alguém improdutivo e/ou alguém que não apresenta risco de vir a ser um concorrente ou ameaça no mercado de trabalho, provocando sentimento de piedade nas pessoas (Fiske et al., 2002). Dentre essas barreiras, encontra-se o ableism ou capacitismo que se caracteriza como uma forma de discriminação social e de preconceito contra às pessoas com deficiência, estereotipando-as como incompetentes e dependentes. Essa forma de discriminação pode provocar também uma série de reações que incluem medo, desprezo e piedade em relação à essas pessoas (Nario Redmond \& Silverman, 2020).

Há vários estudos que abordam crenças negativas em relação às pessoas com deficiência no mercado de trabalho, além das percepções dos outros junto às elas como pessoas dependentes, incompetentes e/ou improdutivas (CarvaIho-Freitas \& Marques, 2007; Colella, DeNisi, \& Varma, 1998; Colella \& Varma, 1999; Maia, Camino, \& Camino, 2011; Stone \& Colella, 1996). De acordo com Carvalho-Freitas e Stathi, (2017); Ren, Paetzold e Colella, (2008); Stone e Colella, (1996) o desempenho, ou seja, a competência no ambiente laboral é um dos problemas mais cruciais quando as pessoas com deficiência passam a fazer parte de um grupo de trabalho, razão que pode intensificar a discriminação e o preconceito junto a essas pessoas. Esse fato pode ser corroborado pela pesquisa de Carmo, Gilla e Quitério (2020) que constataram uma falta de confiança das empresas na capacidade produtiva das pessoas com deficiência.

Estudos sobre cognição social tem demonstrado sucessivamente que a cordialidade e a competência percebidas são duas dimensões universais da cognição social humana, tanto no nível individual quanto no nível grupal, sendo estereótipos importantes para o entendimento do preconceito intergrupal (Fiske et al., 2002). Pesquisas mostram que as pessoas, de qualquer lugar, diferenciam as outras associando cordialidade (confiabilidade, sinceridade) e competência (eficiência, capacidade) (Fiske et al., 2007).

O Stereotype Content Model (SCM) - O modelo de conteúdo de estereótipo (MCE) proposto por Fiske et al., (2002) diferencia tipos de comportamentos discriminatórios como resultado dos estereótipos de competência-cordialidade e 


\section{M." INTERACÃO EM PSICOLOGIA}

das emoções intergrupais. Esse modelo identifica as pessoas com deficiência no agrupamento percebido como tendo baixa competência e alta cordialidade (estereótipo), estando associada à emoção de piedade e comportamentos paternalistas. Ampliando esses resultados, Cuddy et al. (2007) mapearam as combinações de estereótipos (cordialidade e competência) e as emoções (piedade, admiração, inveja e desprezo) em quatro classes de tendências de comportamentos discriminatórios ao longo de duas dimensões (ativo-passivo e facilitador-prejudicial). De acordo com esse estudo realizado, os pesquisadores identificaram as pessoas com deficiência no agrupamento "piedade", em que predomina a percepção de baixa competência e alta cordialidade, evocando duas tendências de comportamento (viés ambivalente): facilitação ativa (ajuda e proteção) e passividade prejudicial (passiva segregação, falha para contratar membros de grupos específicos, negligência para com o bem estar de membros dos grupos, evitação, rebaixamento etc.). Os resultados desta pesquisa utilizando-se do BIAS (Behaviors from Integroup Affect and Stereotypes) Map - Mapa de Comportamento de afetos e estereótipos intergrupal (Cuddy et al., 2007) auxiliam no entendimento de diversos aspectos identificados em pesquisas relacionadas à inserção de pessoas com deficiência no trabalho (Carvalho-Freitas \& Marques, 2009; Carvalho-Freitas et al., 2010; Chima, 1998; Dipboye, R. L., \& Colella, 2012; Nepomuceno \& Carvalho-Freitas, 2008; Stone \& Colella, 1996).

Esses resultados, descritos anteriormente, e identificados em relação às pessoas com deficiência levam as pessoas, de uma maneira geral, a preferirem não trabalhar com esse grupo minoritário (Dipboye, R. L., \& Colella, 2012), diminuindo as possibilidades de contato intergrupal. Por sua vez, o pequeno contato com esse grupo reforça os preconceitos existentes, retroalimentando o processo de discriminação (Fichten et al., 2005). A falta de oportunidade de convivência com pessoas com deficiência também explicita o que Hughes (2012) denuncia como um processo social que faz parte da história da civilização e que tende a manter essas pessoas em espaços segregados ou a tentar torná-las as mais idênticas possíveis às pessoas sem deficiência. Essa segregação transforma o contato inicial com esse grupo minoritário em um processo permeado de insegurança e ansiedade (Hughes, 2012).

Por outro lado, em função da Lei de Cotas ou leis antidiscriminação, o contato com pessoas com deficiência no trabalho passa a ser uma possibilidade real e não objeto de escolha. Essa situação tem desafiado as organizações a criar condições favoráveis ou situações de sensibilização que facilitem o contato com elas (Carvalho-Freitas \& Marques, 2007). De acordo com a Lei Brasileira de Inclusão - LBI, considera-se discriminação, em razão da deficiência, toda forma de distinção, restrição ou exclusão com o propósito de prejudicar e impedir o reconhecimento das pessoas com deficiência (Brasil, 2015).

\section{Maristela Ferro Nepomuceno e Maria Nivalda de Carvalho-Freitas}

É fundamental destacar que a reserva de vagas para concursos públicos para as pessoas com deficiência é uma forma de discriminação positiva visando minimizar exclusões históricas (Gugel, 2006). É inegável a importância desse dispositivo legal que obriga as organizações a contratarem pessoas com deficiência por meio dos processos seletivos ou concursos públicos, possibilitando o acesso ao mercado de trabalho (Oliveira et al., 2006).

Considerando esse cenário, verifica-se que há pouca atenção na literatura brasileira sobre a Lei de Cotas do ponto de vista do Modelo de Conteúdo de Estereótipos (cordialidade e competência) Fiske, Cuddy, Glick e Xu (2002) e das investigações conduzidas por Cuddy, Fiske e Glick (2007). Essa pesquisa pretende contribuir para a diminuição dessa lacuna, utilizando-se dessa perspectiva de análise dos estereótipos, para compreender a inclusão de pessoas com deficiência no trabalho. Nesse sentido, o objetivo da presente investigação é compreender a percepção dos servidores públicos a respeito da Lei de Cotas para as pessoas com deficiência e os estereótipos atribuídos à elas

\section{MÉTODO}

Esta pesquisa foi realizada de acordo com os procedimentos éticos envolvendo seres humanos, tendo sido aprovada pelo Comitê de Ética em Pesquisa: CAAE: 94280318.5.0000.5151. Todos os participantes participaram voluntariamente da pesquisa tendo assinado o Termo de Consentimento Livre e Esclarecido.

O método utilizado para a realização deste estudo foi a abordagem qualitativa, por meio da análise de conteúdo Bardin (1994), tendo como referência a teoria do Modelo de Conteúdo de Estereótipo (MCE) proposto por Fiske, Cuddy, Glick e Xu (2002). A técnica de coleta de dados utilizada foi a entrevista semiestruturada para dar voz aos atores sociais, visando permitir uma compreensão da realidade humana por meio de discursos, sendo adequada para investigações nas quais o objetivo é identificar a maneira como as pessoas percebem algo ou o mundo ao redor (Fraser \& Gondim, 2004)

\section{PARTICIPANTES}

A amostra se constituiu de 38 técnicos administrativos sem deficiência, a saber, técnicos administrativos, chefias, colegas de trabalho e os pró-reitores de uma instituição de ensino superior do Estado de Minas Gerais e 6 técnicos administrativos com deficiência, totalizando 44 entrevistas. A caracterização dos sujeitos entrevistados indicou que $50 \%$ era do sexo masculino e $50 \%$ do sexo feminino; $45 \%$ era colega de trabalho, $40 \%$ chefe e $15 \%$ de pessoas com deficiência. Com relação a idade dos respondentes, $63 \%$ tinham de 41 a 
50 anos de idade e $18 \%$ mais de 50 anos. $61 \%$ eram casados $58 \%$ desse grupo possuía especialização e $74 \%$ eram católicos. 0 critério escolhido para a seleção dos participantes eram pessoas que trabalhavam diretamente com as pessoas com deficiência, a chefia imediata, todos os pró reitores da instituição de ensino e as próprias pessoas com deficiencia. Optou-se por realizar este estudo em uma universidade por se tratar de um local onde as pessoas recebem formação, detêm o conhecimento e onde são formados gestores para trabalhar com pessoas com deficiência e possíveis colegas de trabalho.

\section{INSTRUMENTOS}

Foram realizadas entrevistas semiestruturadas e aplicado um questionário de caracterização do respondente. As perguntas foram direcionadas para as pessoas com deficiência e para as suas respectivas chefias imediatas e alguns colegas de trabalho do mesmo setor, a saber: 1. Que percepção você acha que, as pessoas de uma maneira geral, possuem a respeito da reserva de vagas (Lei de Cotas) para a pessoa com deficiência em concurso público? 2. Que percepção você possui a respeito da reserva de vagas (Lei de Cotas) para a pessoa com deficiência em concurso público? 3. Como você se sentiu ao prestar o concurso público com reserva de vagas para as pessoas com deficiência? Por quê?

As entrevistas com os gestores e colegas de trabalho tiveram o intuito de verificar a percepção deles a respeito da Lei de Cotas para as pessoas com deficiência e a percepção que eles acreditavam que os outros tinham a respeito da Lei. As pesquisas indicam um viés de desejabilidade social nas investigações sobre minorias em geral (Dipboye, R. L., \& Colella, 2012), então, utilizou-se o artifício de perguntar a percepção deles e como viam a percepção das demais pessoas, para tentar minimizar esse viés. Abrams, Swift e Mahmood (2016) ressaltam a dificuldade em identificar os efeitos dos estereótipos uma vez que eles não são discutidos ou mencionados explicitamente. Para os autores, há algumas pressões tanto sociais quanto psicológicas, que afetam as pessoas ao expressarem ou não o preconceito: a) o primeiro ponto é a questão de ser "socialmente desejável" e b) o segundo é a preocupação pessoal, o medo de ser prejudicado no local de trabalho. Uma forma indireta para a superação da desejabilidade social é se concentrar nas normas sociais, ou seja, pedir às pessoas para dizer o que elas acreditam que a maioria das pessoas pensam, diz ou faz sobre determinado assunto, conforme realizado nas pesquisas de Fiske et al., (2002); Louvet et al., (2009). Este procedimento foi adotado na presente pesquisa. A entrevista com as pessoas com deficiência teve o objetivo de identificar os sentimentos delas ao prestar o concurso com a reserva de vagas.

As entrevistas tiveram como finalidade mapear as percepções sobre a deficiência e sobre a Lei de Cotas e as possibilidades de ações para a inserção dessas pessoas em concursos públicos. Ao utilizar a abordagem qualitativa, buscou-se um aprofundamento da produção de conhecimento dessa realidade por meio da utilização de entrevista.

\section{PROCEDIMENTOS DE COLETA E DE ANÁLISE DE DADOS}

Os dados desta pesquisa foram coletados dentro de uma instituição de ensino superior no estado de Minas Gerais. As respostas dos entrevistados foram anotadas durante a entrevista, e ao término, as respostas das questões eram retomadas com o entrevistado, lendo e verificando os principais pontos ressaltados para certificar se o entendimento estava correto (validação subjetiva).

As análises das entrevistas foram realizadas tendo como referência o conteúdo temático das questões. As respostas foram categorizadas tendo por critério a semelhança de conteúdo, de acordo com Bardin (1994). Inicialmente, foi realizada uma leitura flutuante das entrevistas; em seguida, foi elaborada uma tabela com temas e subtemas contendo as falas dos respondentes. Estas foram agrupadas em categorias tendo por critério aspectos que caracterizassem um conjunto de falas. Por exemplo, várias pessoas falaram, de diferentes formas, que a Lei de Cotas não respeitava os direitos iguais de todos ou que favorecia as pessoas com deficiência, considerando que as pessoas sem deficiência tinham feito grandes esforços para serem aprovados nos concursos. Esse conjunto de respostas foram agrupadas na categoria "violação do princípio da isonomia". Além disso, para verificar as percepções estereotipadas foi utilizado o Modelo de Conteúdo de Estereótipo (MCE) que identifica duas dimensões cognitivas: cordialidade e competência, propostas por Fiske, et. al, (2002), buscando identificar percepções resultantes dos estereótipos de competência-cordialidade e suas possíveis consequências para o trabalho de pessoas com deficiência admitidas a partir da Lei de Cotas. Assim, entender como ocorre o processo de percepção humana, considerar as atitudes e as percepções das pessoas de um modo geral e, delas mesmas como categoria de análise, são aspectos importantes para a compreensão da dimensão psicossocial da realidade humana, do fenômeno do preconceito e nos estereótipos atribuídos as pessoas com deficiência.

\section{RESULTADOS E DISCUSSÃO}

\section{PERCEPCÃO DOS COLEGAS E CHEFIAS DAS PESSOAS COM DEFICIENCIA}

Constatou-se que a maioria dos respondentes se mostrou favorável à existência da Lei de Cotas e acredita em sua importância para garantir o acesso de pessoas com deficiência no mercado de trabalho. No entanto, do total de entrevistados, 


\section{WH MTERAC̄̈OEM PSICOLOGIA}

$35 \%$ apresentaram críticas à Lei. Considerando a importância da identificação das críticas à Lei de Cotas para a compreensão dos estereótipos em relação às pessoas com deficiência, essas respostas foram agrupadas em categorias desfavoráveis à adoção das Cotas, visando identificar possíveis justificativas relacionadas às resistências à inserção desse grupo no mercado de trabalho.

Vale destacar que, compreender as percepções distorcidas dos respondentes em relação a Lei de Cotas para as pessoas com deficiência auxilia a ampliar o leque de conhecimento dos possíveis entraves enfrentados por esse grupo minoritário. Esse conjunto de informações possui grande importância para a promoção de estratégias inclusivas, como treinamentos e sensibilização organizacional para os gestores e as pessoas que lidam diretamente com esse grupo oprimido socialmente para reduzir as diferenças sociais (Barnes et al., 2002). As categorias desfavoráveis serão apresentadas a seguir, conforme a Tabela 1 .
A categoria Violação do princípio da isonomia pode ser exemplificada por meio da fala do seguinte respondente "Existe uma opinião contrária, as pessoas criticam a lei, eu percebo pelas ligações das pessoas, elas acham que é uma forma de burlar a lei" (Colega de trabalho da pessoa com deficiência 02). Nesse sentido, a existência da Lei de cotas, adotadas especificamente para inserir esse grupo na instituição pública passa a ser vista pelos respondentes como algo que viola um princípio legal, que infringe a questão dos direitos, sendo, portanto, ilícito na visão de alguns respondentes.

Em seguida, podem-se identificar as categorias Privilégio de pessoas com deficiência com 33\% e Exclusão de pessoas sem deficiência com 24\%. A categoria Privilégio de pessoas com deficiência pode ser exemplificada pelo seguinte relato "No meu setor penso na acessibilidade, tenho de pensar sempre no deficiente. Eles acham que não, tem que ter. Toda vez que põe cota, limita o número de vagas e o brasileiro precisa de emprego. Não é o caso da instituição, não se aplica aqui,

Tabela 1. Categorias desfavoráveis à adoção de cotas para pessoas com deficiência

\begin{tabular}{|c|c|c|c|c|c|}
\hline & \multirow{2}{*}{ Descrição } & \multicolumn{2}{|c|}{ Percepção da sociedade } & \multicolumn{2}{|c|}{ Percepção do respondente } \\
\hline & & Freq. & $(\%)$ & Freq. & $(\%)$ \\
\hline 1 & Violação do princípio da isonomia & 16 & $35 \%$ & 10 & $28 \%$ \\
\hline 2 & Privilégio de pessoas com deficiência & 15 & $33 \%$ & 6 & $17 \%$ \\
\hline 3 & Exclusão de pessoas sem deficiência & 11 & $24 \%$ & 6 & $17 \%$ \\
\hline 4 & Fere o princípio da meritocracia & 8 & $17 \%$ & 7 & $19 \%$ \\
\hline 5 & Diminui a qualificação da mão de obra no trabalho & 7 & $15 \%$ & 8 & $22 \%$ \\
\hline 6 & Desconhecimento/neutralidade & 6 & $13 \%$ & 1 & $3 \%$ \\
\hline 7 & Desqualificação das pessoas com deficiência & 4 & $9 \%$ & 4 & $11 \%$ \\
\hline 8 & Estigmatização das pessoas com deficiência & 4 & $9 \%$ & 9 & $25 \%$ \\
\hline 9 & Ambiguidade & 4 & $9 \%$ & 13 & $36 \%$ \\
\hline 10 & $\begin{array}{l}\text { Não é possível identificar precisamente alguns } \\
\text { tipos de deficiência }\end{array}$ & 3 & $7 \%$ & 5 & $14 \%$ \\
\hline 11 & Caridade & 3 & $7 \%$ & 6 & $17 \%$ \\
\hline
\end{tabular}

Fonte: Elaborado pelos autores.

Das 38 pessoas entrevistadas, frente à primeira pergunta feita aos participantes da pesquisa: Que percepção você acha que, as pessoas de uma maneira geral, possuem a respeito da reserva de vagas (Lei de Cotas) para a pessoa com deficiência em concurso público? Constatou-se que $35 \%$ dos respondentes afirmaram que as pessoas, de um modo geral, são contra a lei, pois viola o princípio da isonomia (vide Tabela 1). 0 fato de tal discurso aparecer em mais de um terço das respostas às entrevistas pode significar que, a reserva de vagas é vista pelo meio social a que pertencem como uma forma de ferir o direito legal, no qual todos são iguais perante a lei sem qualquer distinção. só lá fora, aqui a gente pensa" (Colega de trabalho da pessoa com deficiência 01). Nota-se uma contradição na fala do entrevistado, pois, ao mesmo tempo em que se afirma que a cota retira a vaga de alguém que também precisa de trabalho, o respondente defende a instituição colocando-a fora dessa lógica de análise. Essa categoria ressalta que a percepção a respeito da Lei de Cotas para pessoas com deficiência em concurso público é percebida como um privilégio, ou seja, uma vantagem concedida especificamente a esse grupo, com prejuízo de outros. 


\section{4.' INTERACÃO EM PSICOLOGIA}

$\mathrm{Na}$ categoria Exclusão de pessoas sem deficiência um exemplo pode ser verificado:

nunca chegou nenhuma reivindicação até aqui. As pessoas elogiam que ótimo que a pró-reitoria está fazendo isso. Não há resistência não, nem a cota e nem ao portador. Já ouvi candidato falando com pesar. 0 deficiente concorre entre eles e a concorrência é muito menor entre eles, nesse sentido os outros reclamam. As pessoas acham um pouco injusto, eles tinham que ser tratados todos iguais, eles não têm diferença nenhuma. Um candidato disse: isso é discriminar, porque eles não têm nenhuma diferença intelectual, o raciocínio é o mesmo (Chefia 01).

Esse relato deixa entrever uma contradição, pois o respondente inicia um diálogo afirmando que há uma negação de reclamações no setor em que trabalha a respeito da entrada por meio desse sistema, mas, logo em seguida, revela que os outros têm a percepção de que a Lei de Cotas exclui as pessoas sem deficiência, concedendo um privilégio a esse grupo mesmo quando não seria, segundo o respondente, necessário, já que não existe comprometimento intelectual. Esse fato ratifica as reflexões de Scott (2005) ao afirmar os paradoxos a respeito da igualdade: sendo vista como um princípio absoluto e uma prática contingente; identidades de grupo definem indivíduos e negam a expressão ou percepção plena de sua individualidade; reivindicações por igualdade, demandas por inclusão, ao mesmo tempo, negam e reproduzem a discriminação.

Percebe-se que essas três categorias, que mais foram citadas, estão relacionadas, pois tanto o Privilégio de pessoas com deficiência quanto a Exclusão de pessoas sem deficiência de modo diferenciado ferem, segundo eles, o princípio da isonomia.

Além disso, $17 \%$ das respostas se encaixam na categoria, Fere o princípio da meritocracia, pois afirmam que os outros creem que as cotas deixam de proporcionar uma maior justiça, uma vez que as distinções não ocorrem por sexo, raça ou posição social, mas por competição entre os indivíduos, conquistadas, em tese, com base no conhecimento. Essas respostas se encaixam nessa categoria de acordo com a seguinte fala "acho que os outros pensam que não é justo segurar a vaga de outra pessoa, acham que não é a cota que mostra que o deficiente tem capacidade" (Chefia 02). Com base nesse fragmento, torna-se clara a crença do respondente de que quando os outros utilizam a Cota não demonstram seus méritos.

Verificou-se que todas essas categorias exemplificadas anteriormente expressam percepções e formas de lidar com o outro e ao mesmo tempo, estão de acordo com pesquisas internacionais que abordam as duas dimensões principais do conteúdo de estereótipos, a teoria MCE conforme visto nas pesquisas de Cuddy, Fiske, e Glick (2008) e de Cuddy et al.(2009); Fiske et al. $(2007,2002)$ no qual afirmam que os estereótipos decorrem de fenômenos comuns a todos os
Maristela Ferro Nepomuceno e Maria Nivalda de Carvalho-Freitas

seres humanos. Os autores afirmam também que, quando as pessoas se deparam com membros que não pertencem ao grupo, em geral, elas fazem duas perguntas: Eles pretendem me prejudicar? E eles são capazes de me prejudicar? Como por exemplo, na dimensão cordialidade (amigável, bom humor, sincero e cordial) e na dimensão da competência (capaz, competente, confiante e habilidoso), respectivamente (Cuddy et al., 2009). Especificamente nessa pesquisa, as falas demonstraram que a pessoa com deficiência pode ser vista como uma ameaça no local de trabalho, pois está disputando a mesma vaga, em situação que eles consideram injusta, pois a esse grupo é conferido o privilégio de uma concorrência menor, logo, os participantes acreditam que as pessoas com deficiência não tiveram que se empenhar tanto quanto os demais para conseguir estar naquela organização. Dados da World Health Organization (2011) mostram que, em todo o mundo, as pessoas com deficiência apresentam as piores taxas de saúde, taxa de pobreza mais elevada e baixo nível de escolaridade. Verifica-se a existência de uma "deficiência" de pré-requisitos nesse grupo minoritário por não terem tido acesso às mesmas oportunidades que as demais pessoas, tal como apontado no relatório da OMS. Desse modo, a Lei de Cotas para as pessoas com deficiência faz-se necessária devido à condição histórica de exclusão vivida pelas pessoas com deficiência

Em seguida, com 15\%, a categoria Diminui a qualificação da mão-de-obra no trabalho. De acordo com os respondentes, os outros acreditam que a Lei de Cotas para esse grupo em concurso público diminui a qualidade do trabalho, pois privilegia indivíduos menos qualificados. Para os respondentes, enfraquecer a mão de obra pode estar relacionada com as concepções de deficiência que a sociedade possui, como alguém frágil, que precisa do apoio de outro de modo integral, incapaz de contribuir de forma laboral, enxergando o trabalho das pessoas com deficiência com baixa qualidade:

Eu não concordo com a Lei de Cotas para deficiente, porque a execução do serviço no dia a dia, a rotina de trabaIho para pessoas normais não muda, não chega um documento especial para o deficiente no trabalho, não tem documento em Braille, agora se você vai trabalhar em uma APAE é diferente. Os deficientes têm apenas que escolher um trabalho que realmente possam desenvolver sozinhos sem auxílio integral. Seria melhor para seu dia a dia e não seria constrangedor para si mesmo (Colega de trabalho da pessoa com deficiência 01).

Esse relato revela uma contradição presente nos discursos dos respondentes, isto é, quando da participação em concursos e da reserva de vagas, as pessoas com deficiência são vistas como tendo as condições intelectuais e competências. Por outro lado, quando eles focam na organização do trabaIho, aparece a atribuição de condições de trabalho inferiores 


\section{H. INTERACÃO EM PSICOLOGIA}

e específicas relacionadas às pessoas com deficiência. Essa injunção paradoxal reforça as premissas de uma luta por autoconservação (Hobbes, 2014), bem como uma concepção de deficiência embasada no pressuposto da matriz da normalidade (Carvalho-Freitas, 2007). Em geral, quem compartilha dessa matriz costuma ter a visão da pessoa com deficiência como alguém que deve ser segregado, que se desvia do padrão e que deve ser mantido em instituições especializadas. Um fator que reforça o posicionamento do respondente na matriz da normalidade é que a adaptação do local de trabalho para a pessoa com deficiência não é algo a ser cogitado, pois o foco é a deficiência e nesse sentido, o indivíduo se torna um problema. Essa categoria também reforça a teoria do MCE na qual afirma que esse grupo é visto com baixa competência (Cuddy et al., 2008). Importante destacar que Cuddy et al. (2008) afirmam que as pessoas com deficiência são julgadas mais rapidamente pela dimensão da cordialidade do que da competência, no entanto, nessa pesquisa verificou-se que em situações nas quais as pessoas sentem-se ameaçadas, a dimensão da competência se destaca mais rapidamente.

Cerca de $13 \%$ das respostas se encaixaram na categoria Desconhecimento/neutralidade, ou seja, indivíduos que acreditam que os outros desconhecem a Lei ou são neutros a esse respeito. Essa categoria ressalta falas de respondentes que são neutros e que não fizeram uma reflexão sobre o tema "Eu acho que os outros aprovam a lei. Ainda não escutei os outros falando contrário" (Colega de trabalho da pessoa com deficiência 02).

Há três categorias com $9 \%$, quais sejam, Desqualificação das pessoas com deficiência, a estigmatização das pessoas com deficiência e Ambuiguidade. A categoria Desqualificação das pessoas com deficiência, de acordo com a fala dos respondentes, significa a ausência de disposição para aceitá-las, tendo uma atitude expressa, negativa ou hostil em relação às opiniões relacionadas à inclusão desse grupo "Foi uma única forma de contratar essas pessoas dentro do local de trabalho. Porque ninguém colocaria um cego no mercado de trabalho". (Colega de trabalho da pessoa com deficiência 05). A premissa do respondente é de que as Cotas são formas de facilitar o ingresso no mercado de trabalho, afırmando que são privilegiadas pois possuem deficiência. Nesse sentido, quando se considera se foca apenas nas impossibilidades das pessoas com deficiência, desconsidera-se ou não é feita nenhuma reflexão sobre o processo histórico de discriminação e toda a história de vida dessa pessoa, bem como os aspectos socioeconômicos e de acessibilidade que dificultam seu acesso educacional. 0 preconceito e a discriminação representam um grande entrave à inclusão, uma vez que, promovem estigmas e criam estereótipos, dificultando a convivencia e a socialização no local de trabalho (Neves-Silva et al., 2015).

\section{Maristela Ferro Nepomuceno e Maria Nivalda de Carvalho-Freitas}

Já a Estigmatização das pessoas com deficiência, ou seja, criticar, marcar ou rotular pode ser explanada na fala subsequente "Já ouvi comentário que a pessoa deveria concorrer de igual para igual e gente a favor. Principalmente na época de concurso as pessoas dizem "ih, já tem vaga para deficiente, nossa! Menos uma vaga" (Chefia 03). Novamente, a questão da ameaça torna-se explícita (Cuddy et al., 2007).

A categoria Ambiguidade pode ser vista da seguinte forma:

Não vejo discussão sobre isso na mídia, em lugar nenhum. Acho que os outros não se incomodam muito, não sabem que existe isso. No contexto de agora, não vejo questionamento nem a favor, nem contra. Mas eu acho importante existir a cota porque a sociedade é muito preconceituosa, e não a universidade, porque lida com o servidor. A existência da cota é algo natural, mas o convívio com a pessoa com deficiência é difícil para muitos, acredito, por exemplo, nos supermercados as pessoas que embalam, os outros não têm paciência (Chefia 04).

Essa fala indica dois movimentos contraditórios: o primeiro identifica uma ausência de questionamento das pessoas sobre a questão das cotas e a percepção da intolerância e de dificuldade no contato com esse grupo em situação de trabaIho. $O$ segundo identifica a sociedade como preconceituosa e a universidade (que é parte integrante da sociedade) como não preconceituosa. Esses movimentos podem ser vistos como uma dificuldade para admitir o próprio preconceito, então, identifica-se um processo de cisão entre a sociedade em geral e o local ao qual a pessoa pertence (a universidade).

Posteriormente, ao questionar o que a própria pessoa pensa sobre a Lei de Cotas para as pessoas com deficiência com a seguinte questão: Que percepção você possui a respeito da reserva de vagas (Lei de Cotas) para a pessoa com deficiência em concurso público? Pode-se verificar que, conforme Tabela 1, a maioria dos respondentes se encaixam na categoria Ambiguidade (36\%). É interessante notar, o quanto essa categoria se destacou nessa segunda pergunta, pois se pode inferir que falar a respeito do que os outros acham é mais fácil e confortável do que falar de si próprio, da sua própria percepção (Fiske et al., 2002; Louvet et al., 2009).

Por outro lado, é importante destacar também que a maioria dos respondentes se mostraram favorável as Cotas "acho importante, sou a favor, pois o deficiente tem muito mais dificuldades (subir em ônibus...). Porque quando tem deficiente na família, a gente vê o mundo de outra maneira" (Colega de trabalho da pessoa com deficiência 03). Verifica-se uma consciência da dificuldade enfrentada por esse grupo, além de mostrar que por meio do contato a percepção pode ser modificada. Esse resultado está em consonância com as pesquisas que enfatizam a importância do contato positivo com esse grupo (Abrams \& Eller, 2017; Allport, 1954; Pettigrew \& 


\section{MLE INTERACÃO EM L* PSICOLOGIA}

Tropp, 2006). Outro argumento favorável que demonstra a importância do contato está presente no relato "Eu concordo plenamente, aliás acho que tinha que aumentar mais as cotas, fiz parte de comissão aqui. A gente enfrenta muitos argumentos, mas depois que os deficientes entram as pessoas veem que eles dão conta" (Chefia 05).

Embora os respondentes tenham relatado concordar com a Lei de Cotas, em seguida, demonstraram uma discordância, desqualificando a pessoa com deficiência. Por meio das falas dos colegas de trabalho verifica-se uma indisposição deles em lidar com esse grupo, um sentimento de antipatia conforme pode ser visto em Fiske, Cuddy e Glick (2007) e interpretar uma alteração das dimensões sociais do MCE. Segundo Fiske et al (2007) as pessoas com deficiência são vistas com alta cordialidade e baixa competência. No entanto, pode-se notar que com a Lei de Cotas algumas chefias e colegas de trabalho passaram a percebê-las como uma ameaça e a dimensão de cordialidade se modifica passando de alta cordialidade e baixa competência para baixa cordialidade e baixa competência.

Acho boa. Acho que as pessoas se aproveitam para se beneficiar. Acho que se a pessoa tem uma perna torta ela não deve entrar junto com os outros. Eu tenho um colega que nunca teve nada, tentou e agora entrou pela cota e, aparentemente não tem nada. (Colega de trabalho da pessoa com deficiência 06).

Por fim, ao longo da entrevista com as chefias e colegas de trabalho verificou-se que as pessoas se sentiram mais confortáveis em responder à primeira questão do que a segunda questão, pois falar a respeito do que os outros pensam é mais confortável do que falar de si mesmo, ou seja, atribuir aos outros as críticas com relação a Lei, reafirmando a importância de se considerar o procedimento proposto por Fiske et al., (2002); Louvet et al., (2009) para lidar com a questão da desejabilidade social.

\section{PERCEPÇÃO DAS PRÓPRIAS PESSOAS COM DEFICIÊNCIA}

Verificar a percepção das próprias pessoas com deficiência vai ao encontro do slogam difundido mundialmente: Nada sobre nós, sem nós. Estudos que examinam a forma como os grupos desfavorecidos são tratados, como por exemplo, o grupo das pessoas com deficiência, são de extrema importância, pois permitem produzir mudanças na forma de agir e de pensar na sociedade (Barton \& Oliver, 1997).

Neste estudo, seis pessoas com deficiência foram entrevistadas, frente à questão das facilidades e dificuldades em relação ao processo de inserção e integração dentro do local de trabalho por meio da Lei de Cotas, todos os respondentes afirmaram que as cotas facilitam, mas alguns deles não deixaram de ressaltar que, dependendo da deficiência, as pessoas podem ter problemas como pode ser visto na fala desse
Maristela Ferro Nepomuceno e Maria Nivalda de Carvalho-Freitas

respondente: "Em relação a isso é muito complexo, só a inscrição não facilita, vai haver o preconceito. Já escutei muito, entrou pela cota. É uma forma válida de inscrição, mas o preconceito é muito grande, igual as cotas raciais, o preconceito aumenta porque o número de vagas é maior, a sociedade não tem uma visão boa do deficiente que trabalha, não acha que ele é produtivo" (Pessoa com deficiência 03).

Com base na questão dos sentimentos relacionados à participação em concurso público com reserva de vagas para as pessoas com deficiência, um respondente disse que foi sem constrangimento algum, mas os demais disseram ter ficado constrangidos. Esse fato pode ser exemplificado pela seguinte fala "(Risos) acho que ninguém sente bem" (Pessoa com deficiência 01). Para outro respondente a reserva de vagas pode desmerecer ou desqualificar esse grupo "Foi muito importante e significativo, sugiro que este processo/ oferta continue sempre proporcionando as pessoas com deficiência esta oportunidade. As pessoas te olham diferente, fui discriminada porque minha deficiência não "aparecia", muitas pessoas não sabiam e duvidaram da minha pessoa" (Pessoa com deficiência 02). 0 constrangimento explicitado por alguns respondentes corroboram estudos que mostram que algumas pessoas com deficiência evitam identificar-se como parte de um grupo estigmatizado, como estratégia de enfrentamento do estigma e de proteção da propria identidade (Nario-Redmond et al., 2013).

Em relação à percepção do que as pessoas com deficiência achavam que, de uma maneira geral, as pessoas possuem a respeito da reserva de vagas (Lei de Cotas) para a pessoa com deficiência em concurso público, verificou-se, de um modo geral que, as pessoas com deficiência acreditam que a sociedade nutre sentimentos de caridade, acredita que a inclusão pode diminuir a qualificação da mão de obra no trabaIho, possui certo estigma com relação a elas mesmas e, possui uma dificuldade em identificar precisamente alguns tipos de deficiência. Foi constatado semelhanças nas percepções das pessoas com deficiência em relação às chefias e colegas de trabalho entrevistados. Para esse grupo são necessárias mudanças e uma visão melhor da competência das pessoas com deficiência por parte da sociedade em geral "Eu acho que hoje em dia as pessoas aceitam bem o deficiente, mas é preciso mudar a imagem do deficiente, passar de "coitado" que está ali só para preencher a vaga para alguém produtivo e eficiente que está ali acrescentando alguma coisa para a instituição" (Pessoa com deficiência 01).

Essa fala possui uma contradição, pois embora o respondente diga que os outros aceitam as pessoas com deficiência, ele também afirma que é preciso modificar o estereótipo de alguém que elicia sentimento de pena, que não apresenta risco ou ameaça, para alguém que produz e desempenha adequadamente a função no local de trabalho. Essa fala vai ao 


\section{H. INTERACÃO EM PSICOLOGIA}

encontro dos resultados de pesquisa de Cuddy et al., (2009), no qual os autores ressaltam que esses grupos são vistos como incapazes de competir em uma sociedade convencional, por isso a existência das cotas

Houve respondentes que destacaram que a aceitação das pessoas com deficiência no mercado de trabalho não é unânime por parte delas mesmas, tendo ideias diversificadas assim como as demais pessoas sem deficiência "Há uma divisão de pensamentos. Acho que quem trabalha muda a percepção dos outros, isso facilita quebrar preconceitos. É difícil uma pessoa se manifestar comigo em relação a deficiência. As pessoas acham que o deficiente não tem produção e não é produtivo" (Pessoa com deficiência 04). Tanto a produtividade, quanto a competência novamente se revela na fala desse grupo que está em consonância com a literatura apresentada anteriormente sobre o Modelo do Conteúdo do Estereótipo. Foi constatado de um modo geral, que as pessoas com deficiência acreditam que a sociedade nutre sentimentos de caridade, que os outros possuem estereótipos com relação a elas e que possuem dificuldades em identificar precisamente alguns tipos de deficiência.

Pesquisas relacionadas a percepções e estereótipos mostram que a cultura influencia a percepção das dimensões de cordialidade e da competência (Cuddy et al., 2009). Desse modo, é importante compreender como as mudanças na estrutura social influenciam os processos intergrupais (Fiske et al., 2002). Por meio desta pesquisa, pode-se constatar que embora as pessoas tenham uma percepção das pessoas com deficiência com alta cordialidade e baixa competência (Fiske et al., 2002) - as mudanças estruturais instauradas, nesse caso, a Lei de Cotas em concurso público - a percepção com relação a esse grupo de pessoas modifica a dimensão de cordialidade, principalmente, e passa a ser vista como alguém que se enquadraria em baixa cordialidade e baixa competência para algumas chefias e colegas de trabalho. Em outras palavras, a percepção se modifica devido à concorrência e à ameaça dessa situação que gera uma mudança na percepção da dimensão de cordialidade e no sentimento atribuído a esse grupo, passando de piedade e proteção (paternalismo) para um certo desprezo e antipatia

\section{CONSIDERAÇÕES FINAIS}

Essa pesquisa permitiu identificar resistência e contradições relacionadas à reserva de vagas para pessoas com deficiência em concursos públicos. A despeito da inegável história de exclusão do trabalho das pessoas com deficiência ao longo da história (Carvalho-Freitas \& Marques, 2007), esse processo é desconsiderado quando os interesses de autoconservação das pessoas sem deficiência estão em jogo, reiterando a importância do Estado na manutenção de ações afırmativas que assegurem o direito das minorias.

Os resultados identificados contribuem para a constatação de que com a Lei de Cotas, embora explicitamente aprovada pela maioria dos respondentes, é objeto de crítica de parte considerável de indivíduos que a associa a uma quebra do princípio da isonomia. Além disso, as pessoas com deficiência são vistas por alguns respondentes como beneficiadas por uma concorrência menor, tendo que fazer menos investimento para serem aprovadas e modifica a percepção das dimensões de cordialidade desse grupo. Elas deixaram de ser vistas como pessoas de alta cordialidade e passaram a serem vistas como baixa cordialidade no momento da reserva de vagas. A percepção da dimensão social de alta cordialidade para baixa cordialidade se modifica devido tanto à ameaça representada pela redução de vagas disponíveis, como pela associação das pessoas com deficiência no trabalho com uma situação de privilégio que desconsidera o mérito. Desse modo, pode-se dizer que a competição por uma vaga no local de trabalho modifica a dimensão da cordialidade desse grupo.

A pesquisa também permitiu ampliar a compreensão de algumas opiniões estereotipadas contrárias a lei e explicitar algumas contradições na forma de se posicionar com relação a concorrência, bem como os sentimentos e atitudes preconceituosas no local de trabalho. Tomar conhecimento de percepções estereotipadas que prejudicam a inserção do grupo das pessoas com deficiência pode auxiliar na construção de medidas que promovam discussões sobre a inclusão a partir da possibilidade de criação de um novo contrato social (ILO, 2019) em que a garantia de igualdade, distribuição adequada de recursos e o acesso a bens e serviços sejam valores compartilhados por todos.

Embora os resultados tenham se centrado nas críticas à inclusão, constatou-se que a maioria dos respondentes é favorável à Lei de Cotas para pessoas com deficiência, o que mostra um avanço nesse processo. Além disso, identificou-se por meio das categorias desfavoráveis à inclusão que, mesmo entre os respondentes que se posicionam de forma desfavorável à Lei de Cotas, existe uma dificuldade em expressar claramente essa opinião. As estratégias mais utilizadas foram atribuir aos outros a discordância e as críticas à Lei, mantendo um discurso pautado na desejabilidade social. No entanto, o conhecimento dessas opiniões desfavoráveis é importante para se entender as dificuldades de inserção desse grupo no trabalho, trazendo elementos que podem contribuir para realizar treinamentos e sensibilização dentro das organizações, assim como para a realização de futuras pesquisas.

Espera-se que esses resultados possam contribuir para um maior conhecimento do conteúdo dos estereótipos das pessoas com deficiência e das percepções dos colegas de 


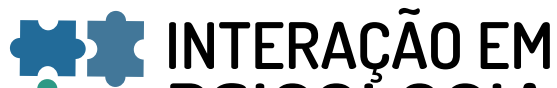 IT PSICOLOGIA}

trabalho, das chefias e das próprias pessoas com deficiência em relação à Lei de Cotas, auxiliando no planejamento de novas possibilidades de intervenções, treinamentos e, por meio do contato com esse grupo minoritário, possam se modificar as percepções negativas estereotipadas e consecutivamente, diminuir o preconceito. 0 estudo possui limitações por ser realizado em apenas uma instituição. Há necessidades de novas pesquisas para verificar se esses resultados são corroborados ou não em outros contextos.

\section{AGRADECIMENTOS}

Os autores agradecem à Universidade Federal de São João del Rei pelo financiamento da pesquisa.

\section{CONTRIBUIÇÃO DE CADA AUTOR}

Certificamos que todos os autores participaram suficientemente do trabalho para tornar pública sua responsabilidade pelo conteúdo. A contribuição de cada autor pode ser atribuída como se segue:

M.F.N. e M.N.C.F. contribuíram para a conceitualização do artigo; M.F.N. contribuiu com investigação, e M.N.C.F contribuiu com supervisão. M.F.N. e M.N.C.F. fizeram a redação do artigo, analisaram os dados e a redação final com as discussões necessárias.

\section{DECLARAÇÃO DE CONFLITOS DE INTERESSES}

Os autores declaram que não há conflitos de interesse no manuscrito submetido.

\section{DECLARAÇÃO DE FINANCIAMENTO}

A pesquisa relatada no manuscrito foi financiada pela Universidade Federal de São João del-Rei- UFSJ.

\section{REFERÊNCIAS}

Abrams, D., \& Eller, A. D. (2017). A temporally integrated model of intergroup contact and threat (TIMICAT). In V. Stathi (Ed.), Intergroup contact theory: recent developments and future directions (Routlege).

Abrams, D., Swift, H. J., \& Mahmood, L. (2016). Prejudice and unlawful behaviour: Exploring levers for change (Issue August). https://doi.org/10.13140/RG.2.1.2676.5047

Allport, G. W. (1954). The nature of prejudice (Cambrigde (ed.)). Perseus Book.
Maristela Ferro Nepomuceno e Maria Nivalda de Carvalho-Freitas

Antonak, R. F., \& Livneh, H. (2000). Measurement of attitudes toward persons with disabilities. DisabilityandRehabilitation, 22, $211-224$. https://doi.org/10.1080/096382800296782

Assunção, R. V., Carvalho-Freitas, M. N., \& Oliveira, M. S. (2015). Satisfação no trabalho e oportunidades de desenvolvimento da carreira entre profissionais com deficiência. Revista Psicologia Organizações e Trabalho, 15(4), 340351. https://doi.org/10.17652/rpot/2015.4.556

Bardin, L. (1994). Análise de Conteúdo. Edições 70.

Barnes, C., Oliver, M., \& Barton, L. (2002). Disability Studies Today. Polity Press.

Barton, L., \& Oliver, M. (1997). Disability studies : past, present and future. The Disability Press.

Brasil. (1991). Decreto no 8.213, de 24 de julho de 1991. Dispõe sobre os Planos de Benefícios da Previdência Social e dá outras providências.

Brasil. (2015). Lei Brasileira de Inclusão. Estatuto da Pessoa com Deficiência - Lei 13.146.

Carmo, M. M. I. B., Gilla, C. G., \& Quitério, P. L. (2020). Um estudo sobre a inclusão de pessoas com deficiência no mercado de trabalho brasileiro. Interação Em Psicologia, 24(01), 448-458.

Carvalho-Freitas, M. . N., \& Marques, A. L. (2009). Pessoas com Deficiência e Trabalho: Percepção de Gerentes e Pós-Graduandos em Administração. Psicologia Ciência e Profissão, 29(2), 244-257.

Carvalho-Freitas, M. N. (2007). A Inserção de pessoas com deficiência em empresas brasileiras - Um estudo sobre as relações entre concepções de deficiência, condições de trabalho e qualidade de vida no trabalho. Tese (Doutorado em Administração), Universidade Federal de Minas Gerais, Belo Horizonte, MG, Brasil.

Carvalho-Freitas, M. N., \& Marques, A. L. (2007). A diversidade através da história: a inserção no trabalho de pessoas com deficiência. Organizações \& Sociedade, 14(41), 59-78. https://doi.org/10.1590/S1984-92302007000200003

Carvalho-Freitas, M. N., \& Stathi, S. (2017). Reducing workplace bias toward people with disabilities with the use of imagined contact. Journal of Applied Social Psychology, 47(5), 256-266. https://doi.org/10.1111/jasp.12435

Carvalho-Freitas, M. N., Toledo, I. D., Nepomuceno, M. F., Suzano, J. C. C., \& Almeida, L. A. D. (2010). Socialização organizacional de pessoas com deficiência. Revista de Administração de Empresas, 50(3), 264-275. https://doi. org/10.1590/S0034-75902010000300003

Carvalho Freitas, M. N., Tette, R. G. P., Souza, G. C., Bentivi, D. R. C., \& Oliveira, M. S. (2019). Percepção de desempenho de pessoas com deficiência e desenho do trabalho. Revista Psicologia: Organizações e Trabalho, 19(4), 781-790. https://doi.org/10.17652/rpot/2019.4.17381 


\section{MLE INTERACÃO EM PSICOLOGIA}

Chima, F. (1998). Workplace and disabilities: opinions on work, interpersonal, and intrapersonal factors. Journal of Applied Rehabilitation Counseling, 29, 31-37.

Cohen, J., Schiffler, F., Rohmer, O., Louvet, E., \& Mollaret, P. (2019). Is disability really an obstacle to success? Impact of a disability simulation on motivation and performance. Journal of Applied Social Psychology, 49(1), 50-59. https:// doi.org/10.1111/jasp. 12564

Colella, A., DeNisi, A. S., \& Varma, A. (1998). The impact of ratee's disability on performance judgments and choice as partner: The role of disability-job fit stereotypes and interdependence of rewards. Journal of Applied Psy chology, 83(1), 102-111. https://doi.org/10.1037/00219010.83.1.102

Colella, A., \& Varma, A. (1999). Disability-Job Fit Stereotypes and the Evaluation of Persons with Disabilities at Work. Journal of Occupational Rehabilitation, 9(2), 79-95. https:// doi.org/10.1023/A:1021362019948

Costa, M. C. A., Carvalho-Freitas, M. N., \& Freitas, M. C. (2019). Qualificação profissional para pessoas com deficiência intelectual: perspectiva dos professores. Revista Educação Especial, 32, 24. https://doi.org/10.5902/1984686x29957

Cuddy, A. J. C., Fiske, S. T., \& Glick, P. (2007). The BIAS map: Behaviors from intergroup affect and stereotypes. Journal of Personality and Social Psychology, 92(4), 631-648. https://doi.org/10.1037/0022-3514.92.4.631

Cuddy, A. J. C., Fiske, S. T., \& Glick, P. (2008). Warmth and Competence as Universal Dimensions of Social Perception: The Stereotype Content Model and the BIAS Map. In Advances in Experimental Social Psychology (Vol. 40, Issue 07, pp. 61149). https://doi.org/10.1016/S0065-2601(07)00002-0

Cuddy, A. J. C., Fiske, S. T., Kwan, V. S. Y., Glick, P., Demoulin, S., Leyens, J.-P., Bond, M. H., Croizet, J.-C., Ellemers, N., Sleebos, E., Htun, T. T., Kim, H.-J., Maio, G., Perry, J., Petkova, K., Todorov, V., Rodríguez-Bailón, R., Morales, E., Moya, M., .. Ziegler, R. (2009). Stereotype content model across cultures: Towards universal similarities and some differences. British Journal of Social Psychology, 48(1), 1-33. https:// doi.org/10.1348/014466608X314935

Dipboye, R. L., \& Colella, A. (2012). Discrimination at work: the Psychological and Organizational bases. In R. L. Dipboye \& A. Colella (Eds.), Discrimination at the Level of the Individual: Cognitive and Affective Factors. Lawrence Erlbaum Associates.

Fichten, C. S., Schipper, F., \& Cutler, N. (2005). Does volunteering with children affect attitudes toward adults with disabilities? A prospective study of unequal contact. Rehabilitation Psychology, 50(2), 164-173.

Fiske, S. T., Cuddy, A. J. C., \& Glick, P. (2007). Universal dimensions of social cognition: warmth and competence. Trends in Cognitive Sciences, 11(2), 77-83. https://doi.org/10.1016/j.tics.2006.11.005
Maristela Ferro Nepomuceno e Maria Nivalda de Carvalho-Freitas

Fiske, S. T., Cuddy, A. J. C., Glick, P., \& Xu, J. (2002). A model of (often mixed) stereotype content: Competence and warmth respectively follow from perceived status and competition. Journal of Personality and Social Psychology, 82(6), 878-902. https://doi.org/10.1037//0022-3514.82.6.878

Fraser, M. T. D., \& Gondim, S. M. G. (2004). Da fala do outro ao texto negociado: discussões sobre a entrevista na pesquisa qualitativa. Paidéia, 14(28), 139-152. https://doi. org/10.1590/S0103-863X2004000200004

Gugel, M. A. (2006). Pessoas com deficiência e o direito ao concurso público: reserva de cargos e empregos públicos, administração pública direta e indireta. Editora da UCG.

Hobbes, T. (2014). Leviatã. Martins Fontes.

Hughes, B. (2012). Fear, pity and disgust: emotions and the non-disabled imaginary. In N. Watson, A. Roulstone, \& C. Thomas (Orgs.), Routledge. In Handbook of Disability Studies (pp. 67-77). Taylor and Francis.

Lewis, G. B., \& Allee, C. L. (1992). The Impact of Disabilities on Federal Career Success. Public Administration Review, 52(4), 389-398.

Louvet, E. (2007). Social judgment toward job applicants with disabilities: Perception of personal qualities and competences. Rehabilitation Psychology, 52(3), 297-303. https:// doi.org/10.1037/0090-5550.52.3.297

Louvet, E., Rohmer, O., \& Dubois, N. (2009). Social Judgment of People with a Disability in the Workplace. Swiss Journal of Psychology, 68(3), 153-159. https://doi.org/10.1024/14210185.68.3.153

Maia, L. M., Camino, C., \& Camino, L. (2011). Pessoas com deficiência no mercado de trabalho: uma análise do preconceito a partir das concepções de profissionais de recursos humanos. Pesquisas e Práticas Psicossociais, 6(1), 78-91.

Nario-Redmond, M. R., Noel, J. G., \& Fern, E. (2013). Redefining Disability, Re-imagining the Self: Disability Identification Predicts Self-esteem and Strategic Responses to Stigma. Self and Identity, 12(5), 468-488. https://doi.org/10.1080/ 15298868.2012.681118

Nario Redmond, M. R., \& Silverman, A. (2020). Contending with Ableism from Internalized Ableism to Collective Action. In Ableism: The Causes and Consequences of Disability Prejudice (First Edit, pp. 220-265). John Wiley \& Sons, Inc. https://doi.org/10.1002/9781119142140.ch6

Nepomuceno, M. F., \& Carvalho-Freitas, M. N. (2008). As crenças e percepções dos gerentes e as possibilidades de trabalho das pessoas com deficiência. Psicologia Em Pesquisa, 2(1), 81-94.

Neves-Silva, P., Prais, F. G., \& Silveira, A. M. (2015). Inclusão da pessoa com deficiência no mercado de trabalho em Belo Horizonte, Brasil: cenário e perspectiva. Ciência \& Saúde Coletiva, 20(8), 2549-2558. https://doi.org/10.1590/141381232015208.17802014 


\section{INTERACÃO EM LFICOLOGIA}

Oliveira, J. M., Araújo, J. N. G., \& Romagnoli, R. C. (2006). Dificuldades relativas à inclusão social das pessoas com deficiência no mercado do trabalho. Latin-American Journal of Fundamental Psychopathology on Line, I(1), 77-89.

Organization, W. H., \& WHO. (2011). World report on disability. In World Health Organization. World Health Organization. https://doi.org/10.1111/j.1468-3148.2012.00693.x

Pereira, C. E. C., Bizelli, J. L., \& Leite, L. P. (2017). Organizações de ensino superior: inclusão e ambiente de trabaIho. Educação \& Sociedade, 38(138), 99-115. https://doi. org/10.1590/es0101-73302017151511

Pettigrew, T. F., \& Tropp, L. R. (2006). A meta-analytic test of intergroup contact theory. Journal of Personality and Social Psychology, 90(5), 751-783. https://doi.org/10.1037/00223514.90.5.751

Ren, L. R., Paetzold, R. L., \& Colella, A. (2008). A meta-analysis of experimental studies on the effects of disability on human resource judgments. Human Resource Management Review, 18(3), 191-203. https://doi.org/10.1016/j. hrmr.2008.07.001

Rezende, M. G., Carvalho-Freitas, \& Vieira-Silva, M. (2016). Crenças, Atitudes e Práticas dos Profissionais de Recursos Humanos Diante do Cumprimento da Lei de Cotas. Interação Em Psicologia, 19(1), 47-59. https://doi.org/10.5380/ psi.v19i1.31553

Ribeiro, M. A., \& Carneiro, R. (2009). A inclusão indesejada: as empresas brasileiras face à lei de cotas para pessoas com deficiência no mercado de trabalho. Organizações \& Sociedade, 16(50), 545-564. https://doi.org/10.1590/S198492302009000300008
Maristela Ferro Nepomuceno e Maria Nivalda de Carvalho-Freitas

Rohmer, O., \& Louvet, E. (2012). Implicit measures of the stereotype content associated with disability. British Journal of Social Psychology, 51(4), 732-740. https://doi.or$\mathrm{g} / 10.1111 / \mathrm{j} .2044-8309.2011 .02087 . x$

Scott, J. W. (2005). O enigma da igualdade. Revista Estudos Feministas, 13(1), 11-30. https://doi.org/10.1590/S0104026X2005000100002

Stone, D. L., \& Colella, A. (1996). A Model of Factors Affecting the Treatment of Disabled Individuals in Organizations. The Academy of Management Review, 21(2), 352. https:// doi.org/10.2307/258666

Suzano, J. C. C., Nepomuceno, M. . F., Ávila, M. R. C., Lara, G. B., \& Carvalho-Freitas, M. . N. (2008). Análise da produção acadêmica nacional dos últimos 20 anos sobre a inserção da inserção da pessoa portadora de deficiência no mercado de trabalho. In M. N. Carvalho-Freitas \& A. L. Marques (Eds.), Trabalho e pessoas com deficiciência: pesquisas, práticas e instrumentos de diagnóstico (Vol. 2, pp. 23-41). Juruá Psicologia.

Vezzali, L., \& Giovannini, D. (2011). Cross-group friendships, social dominance orientation and secondary transfer effect. TPM - Testing, Psychometrics, Methodology in Applied Psychology, 18(3), 181-194.

Data de submissão: 21/02/2020 Data da primeira decisão editorial: 04/05/2020 Aprovado em: 01/06/2020 